\title{
Decarboxylative Cyanation of Aliphatic Carboxylic Acids via Visible- Light Flavin Photocatalysis
}

\author{
Nieves P. Ramirez, ${ }^{a}$ Burkhard König, ${ }^{b}$ Jose C. Gonzalez-Gomez ${ }^{\text {** }}$ \\ ${ }^{a}$ Departamento de Química Orgánica, Facultad de Ciencias and Instituto de Síntesis Orgánica (ISO), Universidad de Ali- \\ cante, Apdo. 99, 03080 Alicante, Spain. \\ ${ }^{\mathrm{b}}$ Faculty of Chemistry and Pharmacy, University of Regensburg, D-93040 Regensburg, Germany \\ Supporting Information Placeholder
}

One-step from Vitamin $B_{2}$<smiles>CCOc1ccccc1OCC(C)=O</smiles>

A Inexpensive and non-toxic

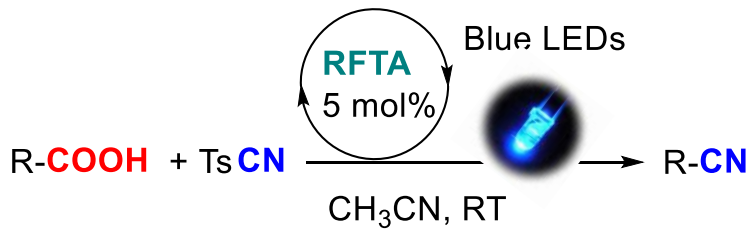

a 1.10 equiv

28 examples

$40-84 \%$ yield

No base, no additives, no metals

\begin{abstract}
An operationally simple method is disclosed for the decarboxylative cyanation of aliphatic carboxylic acids at room temperature. Riboflavin tetraacetate, an inexpensive organic photocatalyst, promotes the oxidation of carboxylic acids upon visiblelight activation. After decarboxylation, the generated radicals are trapped by TsCN, yielding the desired nitriles without any further additive, in a redox-neutral process. Importantly, this protocol can be adapted to flow conditions.
\end{abstract}

Aliphatic nitriles are highly versatile building blocks because they can be easily transformed into different carboxyl derivatives, amines, ketones, aldehydes, iminoethers (Pinner reaction) and a variety of heterocyclic scaffolds in medicinal chemistry. ${ }^{1}$ In addition, nitrile-containing compounds have found important applications in pharmaceuticals, as illustrated in Figure $1 .{ }^{2}$ Consequently, the development of practical protocols for the synthesis of such compounds has attracted considerable attention.

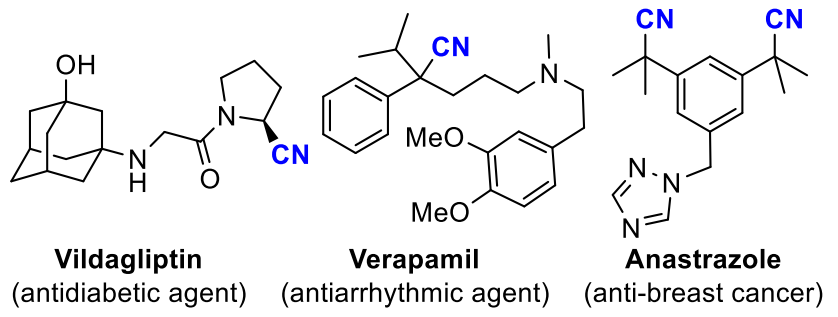

Figure 1. Selected bioactive aliphatic nitriles.

Traditionally aliphatic nitriles have been prepared by nucleophilic substitution of primary alkyl halides, dehydration of pri- mary amides, or dehydration of aldoximes. ${ }^{3}$ More recently, hydrocyanation of olefins ${ }^{4}$ and activation of weak $\mathrm{Csp}^{3}-\mathrm{H}$ bonds (using metal catalysis ${ }^{5}$ or HAT catalysis ${ }^{6}$ ) have become attractive alternatives, because of the readily available starting materials. Another interesting approach is the decarboxylative cyanation of carboxylic acids. Biomass-derived carboxylic acids are inexpensive starting materials, generally stable and nontoxic, that can be transformed into high-value chemicals after extrusion of $\mathrm{CO}_{2}{ }^{7}$ In this context, the acid catalyzed exchange of an carboxylic acid with $\alpha$-methylglutaronitrile at very high temperatures was one of the first successful protocols (Scheme 1a) ${ }^{8}$ Very recently, the treatment of carboxylic acids with an excess of strong bases and electrophilic cyanating reagents proved to be successful for a range of substrates at low temperatures (Scheme 1b). ${ }^{9}$ In 1991 Barton reported the first practical decarboxylative cyanation of the so-called Barton esters and excess of sulfonyl cyanides, under visible light irradiation at room temperature (Scheme 1c). ${ }^{10}$ Despite being effective, Barton`s method still requires an additional step to prepare the ester from carboxylic acids. Direct decarboxylative cyanation offers better step- and atom economy. Substantial development in photoredox catalysis over the past decade enable previously unreachable transformations. ${ }^{11}$ The Waser's group reported the first di- 
rect photocatalytic decarboxylative cyanation of aliphatic carboxylic acids at room temperature, using cyanobenziodoxolone (CBX) as cyanating reagent. ${ }^{12}$ The above mentioned methodology is better suited for $\alpha$-amino or $\alpha$-oxo carboxylic acids and requires the use of an expensive iridium catalyst, in the presence of stoichiometric amounts of cesium benzoate and molecular sieves (Scheme 1d). In order to develop a more cost-effective protocol, we decided to explore organic photocatalysts for this visible-light promoted decarboxylative cyanation. We were particularly attracted by riboflavin ( $\mathrm{RF}$ or vitamin $\mathrm{B}_{2}$ ), a natural compound that is industrially produced by fermentation, ${ }^{13}$ being inexpensive and non-toxic. Importantly, RF is responsible of the redox activity of hundreds of flavo-enzymes. Upon irradiation with visible light irradiation $\left(\lambda_{\max } \sim 450 \mathrm{~nm}\right)$, RF exhibits a moderate luminescence $\left(\lambda_{\max } \sim 510 \mathrm{~nm}\right)$, being. both, the singlet $(2.48 \mathrm{eV})$ and the triplet state $(2.17 \mathrm{eV})$ highly oxidizing. ${ }^{14}$ The photocatalyst is generally involved in oxidations where molecular oxygen is used to regenerate the catalyst (aerobic transformations) $;{ }^{15}$ but is also able to generate singlet oxygen from its triplet state, ${ }^{16}$ allowing energy transfer processes,${ }^{17}$ or even be used as reductant in organic synthesis. ${ }^{18}$ In continuing our investigations of photocatalytic decarboxylative functionalization of carboxylic acids, ${ }^{19}$ we present herein our results on the visible-light promoted decarboxylative cyanation, using riboflavin tetraacetate (RFTA) as photocatalyst and TsCN as cyanating reagent, in the absence of base or any other additive (Scheme 1e).

Scheme 1. Decarboxylative cyanation of aliphatic carboxylic acids.

(a) $\mathrm{R}-\mathrm{COOH}$

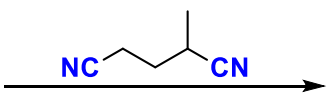

R-CN

$\mathrm{H}_{3} \mathrm{PO}_{4}, 285^{\circ} \mathrm{C}$

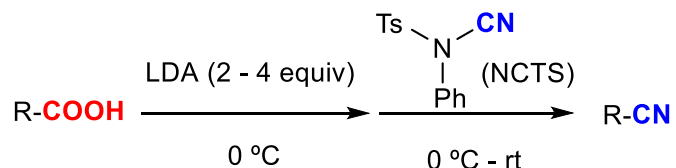

(b)

(c)

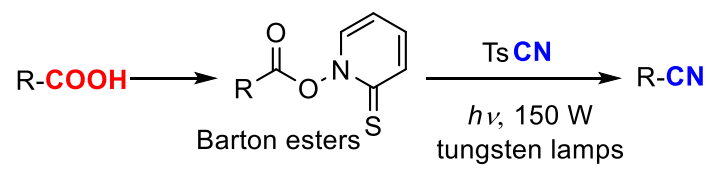

(d)

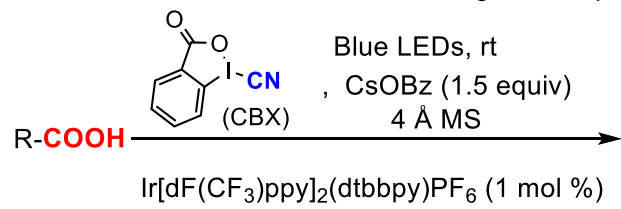

(e) This work

$$
\mathrm{R}-\mathrm{COOH}+\mathrm{Ts} \mathrm{CN} \underset{\text { Blue LEDs, rt }}{\stackrel{\text { RFTA }(5 \mathrm{~mol} \%)}{\longrightarrow}} \mathrm{R}-\mathrm{CN}
$$

RFTA acting as photocatalyst and base

The vast majority of photocatalytic decarboxylative functionalizations of carboxylic acids use stoichiometric bases to facilitate the oxidation of the corresponding carboxylate. However, the Gilmour group has recently reported that cinnamic acids ${ }^{17}$ and biaryl carboxylic acids ${ }^{15 b}$ can be photooxidized using catalytic amounts of RF without any other base. More recently, MacMillan`s group reported that riboflavin tetrabuyrate has a better performance at $\mathrm{pH} 3.5$ for the decarboxylative alkylation of peptides at the C-terminal carboxylic acid site. ${ }^{20}$ Inspired by these results, we decided to develop a protocol in which a riboflavin derivative acts as base and photocatalyst in the decarboxylative cyanation of aliphatic carboxylic acids, avoiding the use of stoichiometric bases. Mechanistically, we anticipated that upon irradiation with visible light $\left(\lambda_{\max } \sim 450 \mathrm{~nm}\right)$ and after rapid intersystem crossing, the long-lived triplet-excited state of flavin would be oxidant enough $\left(\mathrm{E}_{\mathrm{red}}=+1.50 \mathrm{~V} v s \mathrm{SCE}\right)$ to undergo single-electron oxidation of aliphatic carboxylates $\left[\mathrm{E}_{\mathrm{red}}\right.$ from $+1.0 \mathrm{~V}$ to $+1.50 \mathrm{~V}$ vs SCE]. Importantly, the flavin moiety can also act as a base $\left(\mathrm{p} K_{\mathrm{a}}\right.$ of $\left.\mathrm{RFH}^{\circ}=8.3\right)$, favoring the deprotonation of carboxylic acid prior to its single electron oxidation, or in a proton coupled electron transfer (PCET). After rapid decarboxylation of the aliphatic acyloxyl radical $\left(k \sim 10^{9}\right.$ $\left.\mathrm{s}^{-1}\right),{ }^{21}$ the generated radical is intercepted by Ts-CN, affording the desired nitrile and $p$-toluenesulfonyl radical ( $\left.\mathrm{Ts}^{\circ}\right)$, like in the Barton nitrile transfer (Scheme 1c). The latter radical could be reduced by the hydroflavin radical $\left[\mathrm{E}_{\text {red }}\left(\mathrm{Ts}^{*} / \mathrm{Ts}^{-}\right)=-0.50 \mathrm{~V}^{22} v s\right.$ $\mathrm{SCE} ; \mathrm{E}_{\text {red }}\left(\mathrm{RF} / \mathrm{RFH}^{\circ}\right)=-0.60 \mathrm{~V}^{23}$ vs SCE], regenerating the photocatalyst and producing $\mathrm{TsH}$ after protonation, in a redox-neutral process. Alternatively, $p$-toluenesulfonyl radical could abstract a hydrogen atom (HAT) from $\mathrm{FH}^{*}$ to turn-over the photocatalyst (Scheme 2).

\section{Scheme 2. Plausible mechanism.}

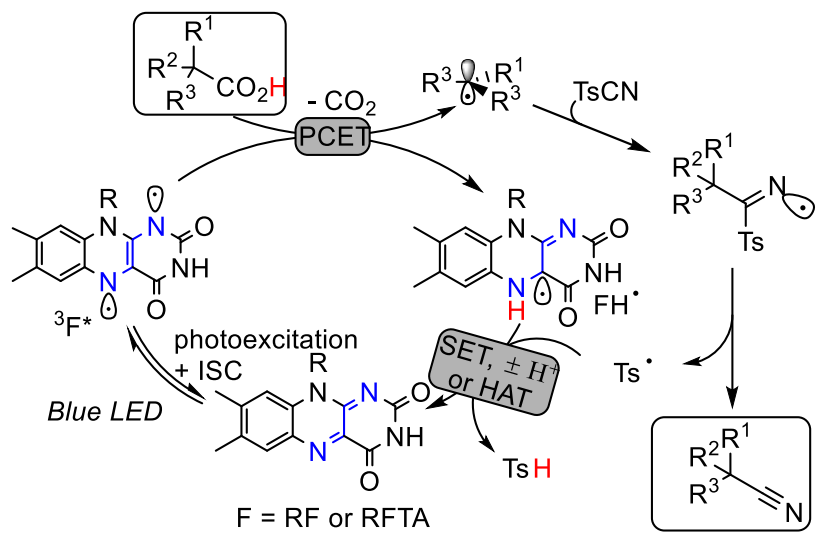

To optimize the photocatalytic decarboxylative cyanation we selected carboxylic acid $\mathbf{1 a}$ as the model substrate (Table S2, in supporting information). When the reaction was conducted in degassed $\mathrm{CH}_{3} \mathrm{CN}$ using RF as catalyst, under blue LED irradiation $\left(\lambda_{\max } 450 \mathrm{~nm}, 15 \pm 2 \mathrm{~mW} / \mathrm{cm}^{2}\right)$ over $12 \mathrm{~h}$ at room temperature, the expected nitrile $\mathbf{2 a}$ was obtained in only $10 \%$ yield (entry 1). However, under identical conditions, the use of riboflavin tetraacetate (RFTA), readily available in one step from RF, allowed the formation of $\mathbf{2 a}$ in excellent yield (entry 2). This result is consistent with the increased photostability, better solubility and more stable $\mathrm{T}_{1}$ state of RFTA compare to RF, resulting in a more efficient oxidizing agent. ${ }^{24}$ Although other solvent systems gave also good results for the model reaction, $\mathrm{CH}_{3} \mathrm{CN}$ afforded the desired product consistently in higher yield (entries 3-5). Increasing the concentration of substrate (entry 6), decreasing the catalyst loading (entry 7 ) or running the reaction in the presence of air (entry 8) has a deleterious impact on the reaction. According to our mechanistic hypothesis, it is not surprising that the presence of $\mathrm{O}_{2}$ from air interferes with the desired process. Encouraged by the previous results, we run the reaction over only $3 \mathrm{~h}$ and we were pleased to observed similar yields for product $\mathbf{2 a}$ (entry 9). As expected, a base was not necessary in the present protocol. In fact, the addition of an organic base (entry 10) or an inorganic base (entry 11) had a negative 
impact on the reaction. We also examined $\mathrm{NaCN}$ and TMSCN as cyanating reagents, but only traces of product $\mathbf{2 a}$ were observed (entries 12 and 13). These experiments indicate that the carbocation pathway is no accessible without an external oxidant. Moreover, CBX also failed under our optimized conditions (entry 14). Control experiments revealed the need of photocatalyst and light for the success of the reaction (entries 15 and 16).

To evaluate the scope of the reaction under optimized conditions (Scheme 3), we first screened different $\alpha$-oxo carboxylic acids. After decarboxylation, a catalytic steady generation of $\alpha$ alkoxyalkyl radicals should be produced, which are nucleophilic enough (high-lying SOMO) to be trapped by electrophilic TsCN. We were pleased to observe than different primary (2b$\mathbf{2 d})$, secondary $(\mathbf{2} \mathbf{a}, \mathbf{2 e})$ and tertiary $(\mathbf{2 g}) \alpha$-aryloxy carboxylic acids gave the corresponding nitriles in moderate to good yields under the optimized conditions. Eventually, $\alpha$-alkoxy carboxylic acids were also good substrates, affording nitriles $\mathbf{2 f}$ and $\mathbf{2 h}$ in good yields. Remarkably, $\alpha$-thio nitrile $2 \mathbf{i}$ was obtained in good yield under these reaction conditions, despite the many possibilities for parasitic reactivity (e.g., further oxidation of the intermediate radical, homocoupling, $\mathrm{H}$-atom abstraction, etc.). In addition, when a ribosic acid derivative was submitted to our standard conditions, nitrile $\mathbf{2} \mathbf{j}$ was obtained as a single isomer with retention of configuration. After decarboxylation, the radical is stabilized by orbital interactions with both axial ring oxygen lone pair and adjacent $\sigma^{*} \mathrm{C}$-O bond (anomeric effect), and should react with $\mathrm{TsCN}$ from the less hindered convex face. ${ }^{25}$ We also explored different natural and unnatural protected $\alpha$ aminoacids in our decarboxylative cyanation protocol. It is worth mentioning that $N$-Boc $\alpha$-aminonitriles are useful reductive carbolithiation precursors that can participate in inter- and intramolecular reactions with electrophiles, as has been elegantly exemplified in the synthesis of natural alkaloids. ${ }^{26}$ Conventional $N$-protecting groups such as Boc, $\mathrm{Cbz}, \mathrm{Bz}$ and Fmoc, were compatible with our reaction conditions, affording the corresponding proline nitriles $(\mathbf{3 b} \mathbf{b}-\mathbf{3 e})$ in moderate yields. ${ }^{27}$ Other monoalkyl substituted $\alpha$-aminoacids (products $\mathbf{3 g}-\mathbf{3 j}$ ), as well as less nucleophilic glycine derivatives (products 3a and 3f), gave the corresponding nitriles in synthetically useful yields. Quaternary $N$-Boc protected aminoacids were less reactive, affording compounds $\mathbf{3 k}$ and $\mathbf{3 l}$ in moderate yield. Interestingly, the tyrosine derivative with an easily oxidized phenol moiety, furnished product $\mathbf{3 m}$ in good yield; likely by a selective PCET from the carboxyl group (more acidic than phenol) to the RFTA*. Moreover, free hydroxyl groups were well tolerated under our reaction conditions in secondary and primary alcohol moieties, obtaining products $\mathbf{3 n}$ and $\mathbf{3 o}$ in moderate to good yields. Finally, a few aliphatic carboxylic acids without heteroatoms in the $\alpha$-position were also examined, furnishing nitriles $\mathbf{4 a}$ to $\mathbf{4 c}$ in moderate yields.

Considering the high molar absorption coefficient of RFTA $\left(\sim 13000 \mathrm{M}^{-1} \mathrm{~cm}^{-1}\right)$ and its concentration in the reaction $(0.005$ M), approximately $90 \%$ of the light is absorbed after within the first $0.2 \mathrm{~mm}$ of the solution. This situation limits the scale of the reaction in batch and we decided to transfer the process to a continuous flow reactor. ${ }^{28}$ After some optimization experiments in the microreactor (PFA tubes, $0.508 \mathrm{~mm}$ internal diameter, $\mathrm{V}$ $=1.70 \mathrm{~mL}$ ), it was found that $36 \mathrm{~min}$ of residence time are sufficient to achieve full conversion of the starting material. Compound 2a was obtained in a slightly diminished yield compare to batch conditions ( $76 \%$ vs $84 \%$ ). These conditions allowed us to prepare $0.53 \mathrm{mmol}$ in $150 \mathrm{~min}$, but a diminished yield was obtained when the reaction was scaled up to $2 \mathrm{mmol}$ (Scheme 4a). ${ }^{29}$ Remarkably, 2-cyano-1,4-benzodioxan (2a) is a convenient synthetic precursor of Idazozan ${ }^{30}$ and WB-4101, ${ }^{31}$ selective antagonists of adrenoreceptors (Scheme $4 \mathbf{b}$ ).

Scheme 3. Decarboxylative cyanation of carboxylic acids ${ }^{a}$

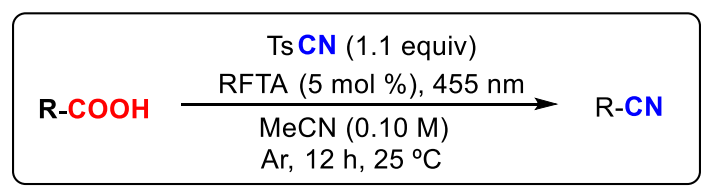

A) From $\alpha$-Oxo- and $\alpha$-Thio- carboxylic acids
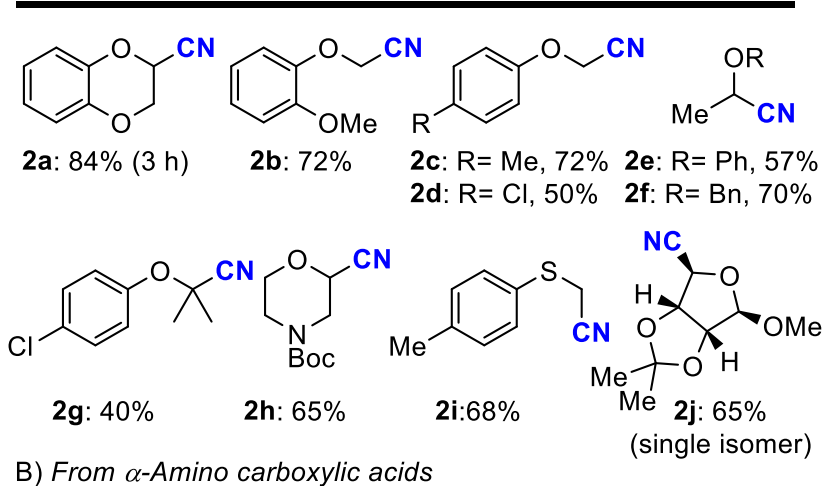

B) From $\alpha$-Amino carboxylic acids

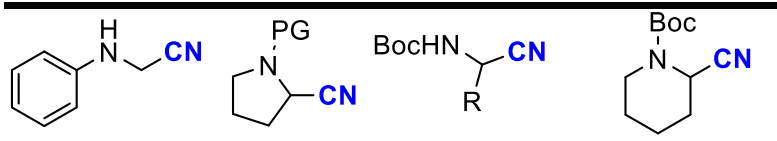

3a: $64 \% \quad 3 b: P G=$ Boc, $40 \% \quad 3 f: R=H, 64 \% \quad 3 j: 84 \%$

(4 h) 3c: $P G=C b z, 48 \% \quad 3 g: R=B n, 55 \%$

3d: $P G=B z, 40 \% \quad 3 h: R=i-B u, 50 \%$

3e: $P G=F m o c, 45 \%$ 3i: $R=\mathrm{CH}_{2} \mathrm{CH}_{2} \mathrm{SMe}, 56 \%$

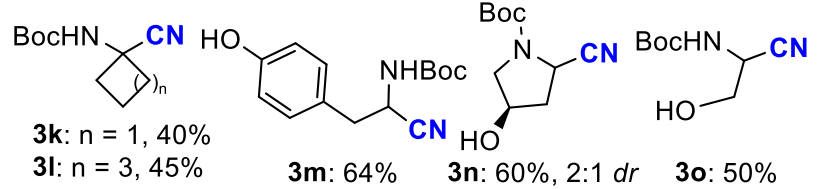

C) From $\alpha-C$ carboxylic acids

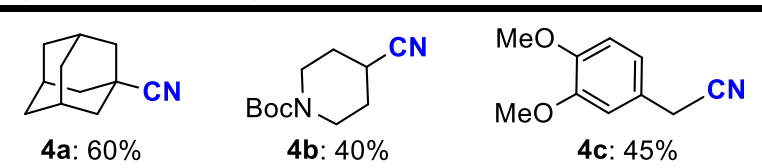

asolated yields are reported for reactions at $0.25 \mathrm{mmol}$ scale.

Scheme 4. Formation of 2 a under flow conditions and formal syntheses of Idazoxan and WB-4101

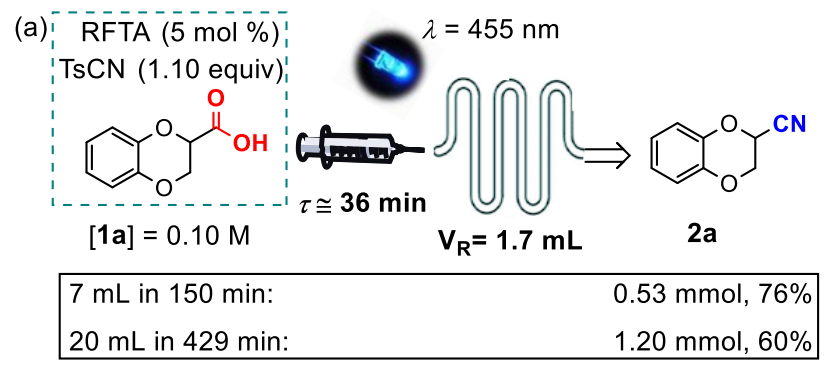

(b)

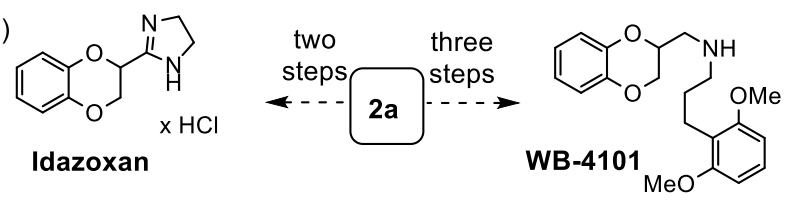


We conducted some control experiments to confirm the postulated reaction mechanism. The decarboxylative cyanation of $1 \mathbf{a}$ was inhibited in the presence of TEMPO, observing the formation of 1a-TEMPO by LC-MS (Scheme 5a). This result is in accordance with the intermediacy of radicals in the reaction. In the GC-MS of crude reaction mixtures we systematically observed peaks with $\mathrm{m} / \mathrm{z} 278$ and 246 that can be assigned to compounds I and II, formed after disproportionation of $p$-toluenesulfinic acid $(\mathrm{TsH}),{ }^{32}$ as indicated in Scheme $5 \mathbf{b}$. Importantly, by-products I and II might also be involved in the oxidation of the hydroflavin radical to close the catalytic cycle of the studied reaction (Scheme 2). Moreover, as revealed in Scheme 5c, the emission intensity of RFTA* is not altered in the presence of $\mathrm{TsCN}$, but is clearly diminished in the presence of carboxylic acid 1a. This dynamic quenching of RFTA* by carboxylic acid 1a supports the PCET to afford the corresponding acyloxy radical as a key step of the proposed mechanism. In addition, from the Stern-Volmer plot using lifetimes of excited RFTA $^{*}$ in the presence of increasing amounts of carboxylic acid 1a (see SI), we determined that this quenching occurs at a rate near the diffusion limit $\left(k_{\mathrm{q}}=3.5 \times 10^{9} \mathrm{M}^{-1} \mathrm{~s}^{-1}\right)$. Finally, the quantum yield for the decarboxylative cyanation of $1 \mathbf{a}$ was very low (Scheme 5d), which strongly suggest that a radical chain mechanism is very unlikely.

\section{Scheme 5. Mechanistic studies}

(a) Radical inhibition

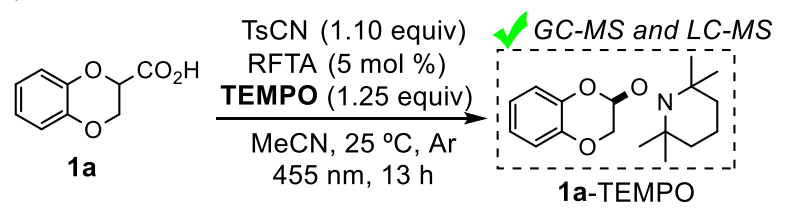

(b) Detection of $\underline{\mathrm{TsH}}$ derivatives in the reaction mixture

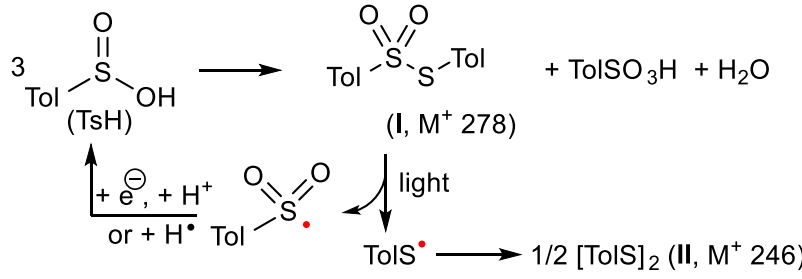

(c) Stern-Volmer plot for RFTA* guenching with 1a or TsCN

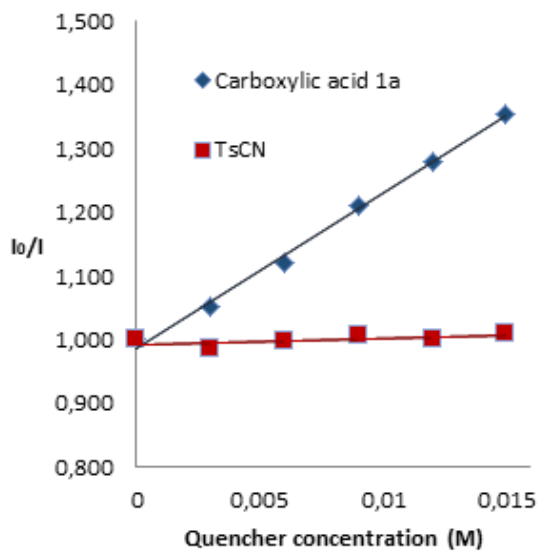

(d) Quantum vield

$$
1 \mathrm{a}+\mathrm{TsCN} \stackrel{\text { RFTA cat., blue LED }}{\longrightarrow} 2 \mathrm{a} \quad \phi=0.2 \%
$$

In summary, we have demonstrated that the decarboxylative cyanation of aliphatic carboxylic acids with TsCN can be efficiently promoted at room temperature, using inexpensive RFTA as photocatalyst and visible-light in the absence of additives. The protocol can be easily transferred from batch to flow conditions and a variety of functional groups is tolerated.

\section{ASSOCIATED CONTENT}

\section{Supporting Information}

The Supporting Information is available free of charge on the ACS Publications website.

Experimental procedures, optimization studies, mechanistic experiments, characterization and NMR spectra of products (PDF)

\section{AUTHOR INFORMATION}

\section{Corresponding Author}

*E-mail: josecarlos.gonzalez@ua.es

Notes

The authors declare no competing financial interest.

\section{ACKNOWLEDGMENT}

This work was generously supported by the Spanish Ministerio de Economía y Competitividad (CTQ2017-88171-P), the Generalitat Valenciana (AICO/2017/007) and the Deutsche Forschungsgemeinschaft (GRK 1626, KO1537/18-1). N. P. R. thanks the EDUA for a mobility grant and Instituto de Síntesis Orgánica for financial support. The authors thank Dr. T. Lana-Villarreal from Universidad de Alicante and Julia Zach from University of Regensburg for helpful assistance during mechanistic investigations.

\section{REFERENCES}

(1) (a) Kukushkin, V. Y.; Pombeiro, A. J. L. Additions to metalactivated organonitriles. Chem. Rev. 2002, 102, 1771-1802. (b) Pearson-Long, M. S. M.; Boeda, F.; Bertus, P. Double addition of organometallics to nitriles: toward an access to tertiary carbinamines. $A d v$. Synth. Catal. 2017, 359, 179-201. (c) Lindsay-Scott, P. J.; Gallagher, P. T. Synthesis of heterocycles from arylacetonitriles: powerful tools for medicinal chemists. Tetrahedron Lett. 2017, 58, 2629-2635.

(2) Fleming, F. F.; Yao, L.; Ravikumar, P. C.; Funk, L.; Shook, B. C. Nitrile-Containing Pharmaceuticals: Efficacious Roles of the Nitrile Pharmacophore. J. Med. Chem. 2010, 53, 7902-7917.

(3) (a) Mowry, D. T. The Preparation of Nitriles. Chem. Rev. 1948, 42, 189-283. (b) For a recent example, see: Ding, R.; Liu, Y.; Han, M.; Jiao, W.; Li, J.; Tian, H.; Sun, B. Synthesis of Nitriles from Primary Amides or Aldoximes under Conditions of a Catalytic Swern Oxidation. J. Org. Chem. 2018, 83, 12939-12944.

(4) (a) Backvall, J. E.; Andell, O. S. Stereochemistry and mechanism of nickel-catalyzed hydrocyanation of olefins and conjugated dienes. Organometallics, 1986, 5, 2350-2355. (b) Gaspar, B.; Carreira, E. M. Mild cobalt-catalyzed hydrocyanation of olefins with tosyl cyanide. Angew. Chem., Int. Ed. 2007, 46, 4519-4522.

(5) For selected examples: (a) Murahashi, S. I.; Nakae, T.; Terai, H.; Komiya, N. Ruthenium-Catalyzed Oxidative Cyanation of Tertiary Amines with Molecular Oxygen or Hydrogen Peroxide and Sodium Cyanide: $\mathrm{sp}^{3} \mathrm{C}-\mathrm{H}$ Bond Activation and Carbon-Carbon Bond Formation. J. Am. Chem. Soc. 2008, 130, 11005-11012. (b) Wagner, A.; Han, W.; Mayer, P.; Ofial, A. R. Iron-Catalyzed Generation of $\alpha-$ Amino Nitriles from Tertiary Amines. Adv. Synth. Catal. 2013, 355, 3058-3070. (c) Huang, M.; Deng, Q.; Gao, Q.; Shi, J.; Zhang, X.; Xiong, Y. Iron-Sulfate-Catalyzed Direct Dehydrogenative Coupling Cyanation of Secondary Phenylamines. Asian J. Org. Chem. 2018, 7, $404-410$.

(6) For selected examples: (a) Hoshikawa, T.; Yoshioka, S.; Kamijo, S.; Inoue, M. Photoinduced Direct Cyanation of C $\left(\mathrm{sp}^{3}\right)-\mathrm{H}$ Bonds. Synthesis 2013, 45, 874-887. (b) Kong, S.; Zhang, L.; Dai, X.; Tao, L.; 
Xie, C.; Shi, L.; Wang, M. DDQ-mediated Direct C( $\left.\mathrm{sp}^{3}\right)$-H Cyanation of Benzyl Ethers and 1,3-Diarylpropenes under Solvent- and Metalfree Conditions. Adv. Synth. Catal., 2015, 357, 2453-2456. (c) Wakaki, T.; Sakai, K.; Enomoto, T.; Kondo, M.; Masaoka, S.; Oisaki, K.; Kanai, M. C $\left(\mathrm{sp}^{3}\right)$-H Cyanation Promoted by Visible-Light Photoredox/Phosphate Hybrid Catalysis. Chem. Eur. J. 2018, 24, 8051-8055.

(7) For a recent comprehensive review, see: Schwarz, J.; König, B Decarboxylative reactions with and without light -a comparison. Green Chem. 2018, 20, 323-361.

(8) (a) Klein, D. A. Nitrile Synthesis via the Acid-Nitrile Exchange Reaction. J. Org. Chem., 1971, 36, 3050-3051. (b) Cantillo, D.; Kappe, C. O. Direct Preparation of Nitriles from Carboxylic Acids in Continuous Flow. J. Org. Chem. 2013, 78, 10567-10571.

(9) Song, F.; Salter, R.; Chen, L. Development of Decarboxylative Cyanation Reactions for C-13/C-14 Carboxylic Acid Labeling Using an Electrophilic Cyanating Reagent. J. Org. Chem. 2017, 82, $3530-3537$.

(10) (a) Barton, D. H. R.; Jaszberenyi, J. C.; Theodorakis, E. A. Radical Nitrile Transfer with Methanesulfonyl Cyanide or $p$-Toluenesulfonyl Cyanide to Carbon Radicals Generated from the Acyl Derivatives of N-Hydroxy-2-Thiopyridone. Tetrahedron Lett. 1991, 32, 3321-3324. (b) Barton, D. H. R.; Jaszberenyi, J. C.; Theodorakis, E. A. The Invention of Radical Reactions -Part XXIII- New Reactions: Nitrile and Thiocyanate Transfer to Carbon Radicals from Sulfonyl Cyanides and Sulfonyl Isothiocyanates. Tetrahedron 1992, 48, $2613-2626$

(11) For recent reviews: (a) Romero; N. A.; Nicewicz, D. A. Organic Photoredox Catalysis. Chem. Rev., 2016, 116, 10075-10166. (b) Staveness, D.; Bosque, I.; Stephenson, C. R. J. Free Radical Chemistry Enabled by Visible Light-Induced Electron Transfer. Acc. Chem. Res., 2016, 49, 2295-2306. (c) Matsui, J. K.; Lang, S. B.; Heitz, D. R.; Molander; G. A. Photoredox-Mediated Routes to Radicals: The Value of Catalytic Radical Generation in Synthetic Methods Development. ACS Catal. 2017, 7, 2563-2575. (d) Marzo, L. M.; Pagire, S. K.; Reiser, O.; König, B. Visible-Light Photocatalysis: Does It Make a Difference in Organic Synthesis? Angew. Chem. Int. Ed. 2018, 57, 10034-10072. (e) Stephenson, C. R. J.; Yoon, T. P.; Macmillan, D. W. C. Visible Light Photocatalysis in Organic Chemistry; Wiley: 2018.

(12) Le Vaillant, F.; Wodrich, M. D.; Waser, J. Room temperature decarboxylative cyanation of carboxylic acids using photoredox catalysis and cyanobenziodoxolones: a divergent mechanism compared to alkynylation. Chem. Sci. 2017, 8, 1790-1800.

(13) Stahmann, K. P.; Revuelta, J. L.; Seulberger, H. Three biotechnical processes using Ashbya gossypii, Candida famata, or Bacillus subtilis compete with chemical riboflavin production. Appl. Microbiol. Biotechnol. 2000, 53, 509-516.

(14) (a) Lu, C.; Lin, W.; Wang, W.; Han, Z.; Yao, S.; Lin, N. Riboflavin $\left(\mathrm{VB}_{2}\right)$ photosensitized oxidation of $2^{\prime}$-deoxyguanosine-5' monophosphate (dGMP) in aqueous solution: a transient intermediates study. Phys. Chem. Chem. Phys. 2000, 2, 329-334. (b) Tan, S. L. J.; Webster, R. D. Electrochemically Induced Chemically Reversible Proton-Coupled Electron Transfer Reactions of Riboflavin (Vitamin B2). J. Am. Chem. Soc. 2012, 134, 5954-5964. (c) Chen, W.; Chen, J.-J.; Lu, R.; Qian, C.; Li, W.-W.; Yu, H.-Q. Redox reaction characteristics of riboflavin: A fluorescence spectroelectrochemical analysis and density functional theory calculation. Bioelectrochemistry 2014, 98, 103108.

(15) (a) Düsel, S. J. S.; König, B. Visible-Light-Mediated Nitration of Protected Anilines. J. Org. Chem. 2018, 83, 2802-2807. (b) Morack, T.; Metternich, J. B.; Gilmour, R. Vitamin Catalysis: Direct, Photocatalytic Synthesis of Benzocoumarins via (-)-Riboflavin-Mediated Electron Transfer. Org. Lett. 2018, 20, 1316-1319.

(16) Nevesely, T.; Svobodova, E.; Chudoba, J.; Sikorski, M.; Cibulka, R. Efficient Metal-Free Aerobic Photooxidation of Sulfides to Sulfoxides Mediated by a Vitamin $\mathrm{B}_{2}$ Derivative and Visible Light. Adv. Synth. Catal. 2016, 358, 1654-1663.

(17) Metternich, J. B.; Gilmour, R. One Photocatalyst, n Activation Modes Strategy for Cascade Catalysis: Emulating Coumarin Biosynthesis with (-)-Riboflavin. J. Am. Chem. Soc. 2016, 138, 1040-1045.
(18) Martinez-Haya, R.; Miranda, M. A.; Marin, M. L. Metal-Free Photocatalytic Reductive Dehalogenation Using Visible-Light: A Time-Resolved Mechanistic Study. Eur. J. Org. Chem. 2017, 2164 2169.

(19) Ramirez, N. P.; Gonzalez-Gomez, J. C. Decarboxylative Giesetype reaction of carboxylic acids promoted by visible-light: a sustainable and photoredox neutral protocol. Eur. J. Org. Chem., 2017, 2154 2163.

(20) Bloom, S.; Liu, C.; Kölmel, D. K.; Qiao, J. X.; Zhang, Y.; Poss, M. A.; Ewing, W. R.; MacMillan, D. W. C. Decarboxylative alkylation for site-selective bioconjugation of native proteins via oxidation potentials. Nat. Chem. 2018, 10, 205-211.

(21) Bockman, T. M.; Hubig, S. M.; Kochi, J. K. Direct Observation of Ultrafast Decarboxylation of Acyloxy Radicals via Photoinduced Electron Transfer in Carboxylate Ion Pairs. J. Org. Chem. 1997, 62, 2210-2221.

(22) (a) Persson, B. Anodic Oxidation of Benzenesulfinate ion. Acta Chem. Scand. 1977, 31B, 88-89. (b) For cyclic voltammetry of TsCN, see: Pirenne, V.; Kurtay, G.; Voci, S.; Bouffier, L.; Sojic, N.; Robert, F.; Bassani, D. M.; Landais, Y. Eosin-Mediated Alkylsulfonyl Cyanation of Olefins. Org. Lett. 2018, 20, 4521-4525.

(23) Depending on the solvents, values ranging from $-0.80 \mathrm{~V}$ to $0.45 \mathrm{~V}$ have been reported. See Reference 18 .

(24) Remucal, C. K.; McNeill, K. Photosensitized Amino Acid Degradation in the Presence of Riboflavin and Its Derivatives. Environ. Sci. Technol. 2011, 45, 5230-5237. The acetylation of the ribose side chain of RF retards its phototautomerization to Lumichrome and prevents the intramolecular HAT process from $\mathrm{T}_{1}$ that compete with the desired SET. The ability of RF to form aggregates through hydrogen bond interactions is also reduced.

(25) (a) Ventre, S.; Petronijevic, F. R.; MacMillan, D. W. C. Decarboxylative Fluorination of Aliphatic Carboxylic Acids via Photoredox Catalysis. J. Am. Chem. Soc. 2015, 137, 5654-5657. (b) Zhou, X.; Wang, P.; Zhang, L.; Chen, P.; Ma, M.; Song, N.; Ren, S.; Li, M. Transition-Metal-Free Synthesis of C-Glycosylated Phenanthridines via $\mathrm{K}_{2} \mathrm{~S}_{2} \mathrm{O}_{8}$-Mediated Oxidative Radical Decarboxylation of Uronic Acids. J. Org. Chem. 2018, 83, 588-603.

(26) Perry, M. A.; Morin, M. D.; Slafer, B. W.; Rychnovsky; S. D. Total Synthesis of Lepadiformine Alkaloids using $N$-Boc $\alpha$-Amino Nitriles as Trianion Synthons. J. Org. Chem. 2012, 77, 3390-3400.

(27) The corresponding proline protected hemiaminals were sideproducts of 3b-3e. No attempts were made to minimize their formation using anhydrous conditions, because this side reaction was significantly less important for other substrates examined.

(28) (a) Garlets, Z. J.; Nguyen, J. D.; Stephenson, C. R. J. The Development of Visible-Light Photoredox Catalysis in Flow. Isr. J. Chem. 2014, 54, 351-360. (b) Cambie, D.; Bottecchia, C.; Straathof, N. J. W.; Hessel, V.; Noël, T. Applications of Continuous-Flow Photochemistry in Organic Synthesis, Material Science, and Water Treatment. Chem. Rev. 2016, 116, 10276-10341.

(29) A similar $61 \%$ yield was obtained when the reaction was run at $2.0 \mathrm{mmol}$ scale under batch conditions (see SI 18). Although the reaction mixture and the microreactor were carefully purged with $\mathrm{N}_{2}$ before the process started, the collecting flask was open and after a prolonged time (>150 min) the diffusion of $\mathrm{O}_{2}$ into the reaction mixture might have a deleterious effect on the reaction yield. To scale up the reaction without a decrease in the yield it might be more appropriate to use a flow reactor of larger volume.

(30) Chapleo, C. B.; Myers, P. L.; Butler, R. C. M.; Doxey, J. C.; Roach, A. G.; Smith, C. F. C. $\alpha$-Adrenoreceptor Reagents. 1. Synthesis of Some 1,4-Benzodioxans as Selective Presynaptic $\alpha_{2}$-Adrenoreceptor Antagonists and Potential Antidepressants. J. Med. Chem. 1983, 26, 823-831.

(31) Dewar, G. H.; Kapur, H.; Mottram, D. R. Some potential $\alpha-$ adrenoreceptor blocking 1,4-benzodioxans and 2,6-dimethoxyphenoxyethylamines. Eur. J. Med. Chem. 1983, 18, 286-290.

(32) Kice, J. L.; Guaraldi, G.; Venier, C. G. The Mechanism of the Disproportionation of Sulfinic Acids. Rate and Equilibrium Constants for the Sulfinic Acid-Sulfinyl Sulfone (Sulfinic Anhydride) Equilibrium. J. Org. Chem. 1966, 31, 3561-3567. 
